\title{
Fluorine in silicate glasses: A multinuclear nuclear magnetic resonance study
}

\author{
T. Schaller, ${ }^{1}$ D. B. Dingwell, ${ }^{1}$ H. KePpler, ${ }^{1 \cdot *}$ W. KNÖller,${ }^{2}$ L. Merwin, ${ }^{1}$ and A. Sebald ${ }^{1}$ \\ ${ }^{1}$ Bayerisches Geoinstitut, Universität Bayreuth, Postfach 101251, W-8580 Bayreuth, Germany \\ ${ }^{2}$ Bruker Analytische Messtechnik, Silberstreifen, W-7512 Rheinstetten, Germany
}

(Received July 15, 1991; accepted in revised form November 20, 1991)

\begin{abstract}
Anhydrous nepheline, jadeite, and albite glasses doped with $\mathrm{F}$ as well as hydrous $\mathrm{F}$-containing haplogranitic glasses were investigated using ${ }^{19} \mathrm{~F}$ combined rotation and multiple-pulse spectroscopy; ${ }^{19} \mathrm{~F} \rightarrow{ }^{29} \mathrm{Si}$ cross-polarization/magic angle spinning (MAS); and high-power ${ }^{19} \mathrm{~F}$ decoupled ${ }^{29} \mathrm{Si},{ }^{23} \mathrm{Na}$, and ${ }^{27} \mathrm{Al}$ MAS nuclear magnetic resonance methods. Fluorine preferentially coordinates with $\mathrm{Al}$ to form octahedral $\mathrm{AlF}_{6}^{3-}$ complexes in all glasses studied. In addition, $\mathrm{F}$ anions bridging two $\mathrm{Al}$ cations, units containing octahedral $\mathrm{Al}$ coordinated by both $\mathrm{O}$ and $\mathrm{F}$, or tetrahedral $\mathrm{Al}-\mathrm{F}$ complexes might be present. The presence of Si-F bonds cannot be entirely ruled out but appears unlikely on the basis of the ${ }^{19} \mathrm{~F} \rightarrow{ }^{29} \mathrm{Si} \mathrm{CP} / \mathrm{MAS}$ spectra. There is no evidence for any significant coordination of $\mathrm{F}$ with alkalis in the glasses studied. ${ }^{23} \mathrm{Na}$ spectra are identical for the samples and their F-free equivalents and the spectra do not change upon decoupling of ${ }^{19} \mathrm{~F}$. The speciation of $\mathrm{F}$ in the hydrous and anhydrous glasses appears to be very similar. Over the range of $\mathrm{F}$ contents studied (up to $5 \mathrm{wt} . \%$ ), there seems to be hardly any dependence of $F$ speciation on the concentration of $F$ in the samples. The spectroscopic results explain the decrease of the viscosity of silicate melts with increasing $\mathrm{F}$ content by removal of $\mathrm{Al}$ from bridging $\mathrm{AlO}_{4}$-units due to complexing with $\mathrm{F}$, which causes depolymerization of the melt. The same mechanism can account for the shift of the eutectic point in the haplogranite system to more feldspar-rich compositions with increasing $\mathrm{F}$ content, and for the peraluminous composition of most F-rich granites. Liquid immiscibility in F-rich granitic melts might be caused by formation of $(\mathrm{Na}, \mathrm{K})_{3} \mathrm{AlF}_{6}$ units in the melt with little or no interaction with the silicate component. The presence of $F$ in granitic melts might increase the solubility of high field strength cations by making nonbridging $\mathrm{O}$ atoms available which form complexes with these cations.
\end{abstract}

\section{INTRODUCTION}

FLUORINE IS ONE OF THE MOST important volatile components of natural magmas, both in mantle-derived melts (e.g., lamproites) and in highly fractionated granitic magmas. Concentrations of several wt.\% are reported in high-fluorine rhyolites (CONGDON and NASH, 1988) and in ongonites (KovalenKo, 1973). Similar to water, the presence of $F$ strongly reduces the viscosity of silicate melts (DINGWELL et al., 1985; DINGWELL, 1989) and increases diffusion coefficients (DINGWELL, 1985). Even small amounts of $F$ in the order of $1 \mathrm{wt} . \%$ will therefore significantly change the transport properties, mobility, and eruption behavior of such magmas. The correlation between high concentrations of certain trace elements ( $\mathrm{Sn}, \mathrm{Zr}, \mathrm{Nb}, \mathrm{Ta}, \mathrm{U}$, Th, etc.) and high $F$ contents in granites and granitic pegmatites ( 1982 ) has stimulated the investigation of phase equilibria in F-containing granitic systems. MANNING (1981) has shown that $F$ strongly lowers both solidus and liquidus temperatures in the haplogranite system and causes a shift of the eutectic point towards more feldspar-rich compositions. Liquid immiscibility in some F-containing granitic systems has been reported by GLYUK and ANFILOGOV (1973) and by ANFILOGOV et al. (1973), whereas KoSTER VAN GROOS and WYLLIE (1968) have not observed this effect. Finally, recent studies (KEPPLER and WYLLIE, 1990) have shown that the presence of $F$ strongly increases the fluid/melt partition coefficients of $U$ and $T h$ in a granite-aqueous fluid system.

\footnotetext{
* Author to whom all correspondence should be addressed.
}

With the exception of one preliminary ${ }^{19} \mathrm{~F}$ nuclear magnetic resonance (NMR) study by HAYASHI et al. (1987) and a recent paper by KOHN et al. (1991), investigations of quenched silicate melts containing $F$ have essentially been based on Raman or infrared spectroscopy (MYSEN and VIRGO, 1985a,b; LUTH, 1988a,b; FOLEY et al., 1986). In addition, X-ray absorption measurements have been used to study the chemical environment of trace elements in F-containing glasses (PONADER and Brown, 1989; FARGES et al., 1991).

Problems commonly encountered in Raman-spectroscopic studies of glasses are band overlap (FLEET, 1986) and the assignment of bands to structural units. While there is general agreement on the assignment of $\mathrm{Si}-\mathrm{O}$ stretching vibrations in silicate glasses to $\mathrm{SiO}_{4}$ tetrahedra with different numbers of nonbridging $\mathrm{O}$ atoms, many other features of the spectra are poorly understood; and quantitative predictions of vibrational bands are hampered by the insufficient knowledge of atomic interaction potentials in these systems (MC MILLAN, 1984). Therefore, interpretations of vibrational spectra of glasses are usually based on the comparison of bands observed in the glasses with those found in crystalline matcrials. Obviously, this method can only be successful if suitable model compounds are available.

NMR, on the other hand, does not allow empirical correlations between resonances observed in the spectra of glasses and those of model compounds; but several sophisticated methods are available that can provide direct information on the existence of chemical bonds between NMR-active nuclei in the sample. These are cross-polarization (PINES et al., 1973; KLEIN DOUWEL et al., 1990) and decoupling 
expcriments. In the present study, both ${ }^{19} \mathrm{~F} \rightarrow{ }^{29} \mathrm{Si}$ crosspolarization (CP/MAS) spectra and ${ }^{19} \mathrm{~F}$ high-power dipolar decoupling experiments of ${ }^{27} \mathrm{Al},{ }^{29} \mathrm{Si}$, and ${ }^{23} \mathrm{Na}$ are described.

Experimental problems associated with ${ }^{19} \mathrm{~F}$ NMR are due to strong dipolar interactions between the ${ }^{19} \mathrm{~F}$ nuclei in the sample, which can broaden the resonances to such an extent that no structural information can be obtained. Additional broadening can result from the anisotropy of the shielding tensor. In order to overcome this problem, combined rotation and multiple-pulse spectroscopy (CRAMPS) was used for measuring ${ }^{19} \mathrm{~F}$ ( TAYLOR et al., 1979). This method yielded much narrower resonances than fast MAS (magic angle spinning) spectra (Fig. 1). The sidebands in fast MAS spectra covered such a large chemical shift range that they would overlap with the resonances of other ${ }^{19} \mathrm{~F}$ nuclei ( Table 1). This problem was even more pronounced in the glasses, where the sidebands were even broader than for the standard compounds due to chemical shift dispersion. Furthermore, when using the fast MAS technique, the resulting spectrum contained a large background signal due to a number of fluorine-containing structural components in the probe. Such background resonances are not present in CRAMPS spectra due to the fact that the pulse sequence is only effective in regions of high $B_{1}$ field homogeneity, i.e., the center of the radio frequency $(\mathrm{RF})$ coil.

The high-power ${ }^{19} \mathrm{~F}$ dipolar decoupled ${ }^{29} \mathrm{Si} \mathrm{MAS}$ and ${ }^{27} \mathrm{Al}$ MAS spectra described in the present paper are the first experiments of this type ever reported. The present paper also contains the first application of the ${ }^{19} \mathrm{~F}$ CRAMPS method to silicate glasses.

\section{SAMPLES}

The samples investigated in this study can be divided into the following two groups:
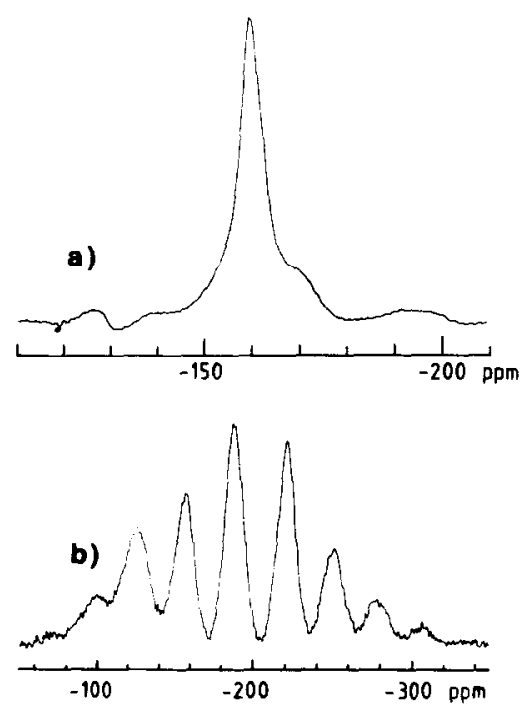

FIG. 1. Comparison of ${ }^{19} \mathrm{~F}$ CRAMPS and fast-spinning single-pulse ${ }^{19} \mathrm{~F}$ MAS spectra for $\mathrm{Na}_{2} \mathrm{SiF}_{6}$. Chemical shifts in ppm relative to $\mathrm{CFCl}_{3}$. (a) ${ }^{19} \mathrm{~F}$ CRAMPS spectrum obtained using the MREV-8 pulse sequence (RHIM et al., 1973). Experimental parameters as in Fig. 2. Sixteen FIDs. (b) ${ }^{19} \mathrm{~F}$ MAS spectra. MAS rate $=8.7 \mathrm{kHz}$; recycle delay $=10 \mathrm{~s} ; 90^{\circ}$ pulse width $-5 \mu \mathrm{s} ; 8$ FIDs.

\begin{tabular}{|c|c|c|}
\hline Compound & $\delta 19 \mathrm{~F} / \mathrm{ppm}$ & Literature data \\
\hline $\mathrm{NaF}$ & -224 & $\begin{array}{l}\text { BURUM et al., } 1978 \\
\text { KREINBRINK et al., } 1990 \\
\text { MEHRING, } 1970\end{array}$ \\
\hline $\mathrm{KF} \cdot 2 \mathrm{H}_{2} \mathrm{O}$ & $\cdot 133$ & $\begin{array}{l}\text { BURUM et al., } 1978 \\
\text { KREINBRINK et ai., } 1990\end{array}$ \\
\hline $\mathrm{A} \mid F_{3}$ & $\cdot 174$ & \\
\hline $\mathrm{Na}_{3} \mathrm{AlF}_{6}$ & -189 & \\
\hline $\mathrm{K}_{3} \mathrm{~A} \mid \mathrm{F}_{6}$ & -190 & \\
\hline $\begin{array}{l}\mathrm{Al}_{2}(\mathrm{~F}, \mathrm{OH})_{2} \mathrm{SiO}_{4} \\
\text { (topaz) }\end{array}$ & - 140 & \\
\hline $\mathrm{Na}_{2} \mathrm{SiF}_{6}$ & -151 & \\
\hline $\mathrm{K}_{2} \mathrm{SiF}_{6}$ & -135 & BURUM et al., 1978 \\
\hline
\end{tabular}

* broad resonance with ill-defined maximum

1) Anhydrous glasses along the join $\mathrm{NaAlO}_{2}-\mathrm{SiO}_{2}$, doped with $\mathrm{F}$. The F-free base compositions of these samples correspond to nepheline $\mathrm{NaAlSiO}_{4}$, jadeite $\mathrm{NaAlSi}_{2} \mathrm{O}_{6}$, and albite $\mathrm{NaAlSi}_{3} \mathrm{O}_{8}$. Approximately $5 \mathrm{wt} \% \mathrm{~F}$ were doped into these compositions, replacing the stoichiometrically equivalent amounts of $\mathrm{O}(2 \mathrm{~F}=$ $1 \mathrm{O})$. Analyses and synthesis methods of these glasses are given elsewhere (DINGWELL et al., 1985). In addition, albite glasses with 1.6 and $3.4 \mathrm{wt} . \% \mathrm{~F}$ were studied.

2) Hydrous haplogranitic glasses. The anhydrous, F-free base composition of these samples corresponds to $35 \mathrm{wt} \% \mathrm{SiO}_{2}, 40 \mathrm{wt} . \%$ $\mathrm{NaAlSi}{ }_{3} \mathrm{O}_{8}$, and 25 wt. $\% \mathrm{KAISi}_{3} \mathrm{O}_{8}$. Between 2 and $5 \mathrm{wt} \% \mathrm{~F}$ replace the stoichiometrically equivalent amount of $O$ in the glasses. Mixtures of an anhydrous gel, $\mathrm{NaF}$, and $\mathrm{AlF}_{3}$ were melted together with $7 \mathrm{wt} . \% \mathrm{H}_{2} \mathrm{O}$ in gold capsules at 2 kbars and $800^{\circ} \mathrm{C}$ using cold seal vessels, and quenched to room temperature within $5 \mathrm{~min}$. Analyses of the glasses for cations and fluorine by electron microprobe using a defocused beam showed that the samples are on composition within the limits of analytical error.

All glasses investigated in this study are clear without any visible crystals and give no X-ray reflections of crystalline phases. In addition to the glass samples, several crystalline compounds containing $F$ were studied, including simple fluorides $\left(\mathrm{NaF}, \mathrm{KF} \cdot 2 \mathrm{H}_{2} \mathrm{O}, \mathrm{NaHF}_{2}\right.$, and $\left.\mathrm{AlF}_{3}\right)$, complex compounds $\left(\mathrm{Na}_{3} \mathrm{AlF}_{6}, \mathrm{~K}_{3} \mathrm{AlF}_{6}, \mathrm{Na}_{2} \mathrm{SiF}_{6}\right.$, and $\left.\mathrm{K}_{2} \mathrm{SiF}_{6}\right)$, and natural minerals (topaz, $\mathrm{Al}_{2}(\mathrm{~F}, \mathrm{OH})_{2} \mathrm{SiO}_{4}$ ).

\section{EXPERIMENTAL}

All NMR spectra were obtained on a modified Bruker MSL-300 spectrometer, using a modified Bruker $4 \mathrm{~mm} \mathrm{CP} /$ MAS double-bearing probe. This system has a magnet operating at a field of $7 \mathrm{~T}$. The relevant nuclei have corresponding Larmor frequencies of ${ }^{19} \mathrm{~F}: 282.404$ $\mathrm{MHz},{ }^{23} \mathrm{Na}: 79.432 \mathrm{MHz},{ }^{27} \mathrm{Al}: 78.206 \mathrm{MHz}$, and ${ }^{29} \mathrm{Si}: 59.630 \mathrm{MHz}$. Experimental details concerning the modification of the spectrometer, set-up procedures for cross-polarization from ${ }^{19} \mathrm{~F}$, and spectroscopic implications of cross-polarization from ${ }^{19} \mathrm{~F}$ at a magnetic field strength of $7 \mathrm{~T}$ are given elsewhere (SEBALD et al., 1992). The experimental conditions used, including pulse length/angle, spinning speed, relaxation delay, and number of transients, are noted in the figure captions. All single-pulse MAS NMR spectra $\left({ }^{23} \mathrm{Na},{ }^{27} \mathrm{Al},{ }^{29} \mathrm{Si}\right)$ were obtained with ${ }^{19} \mathrm{~F}$ high-power dipolar decoupling at a $\mathbf{B}_{1}$ field strength of $\mathrm{ca}$. $50 \mathrm{kHz}$. In fact, for example, for $\mathrm{Li}_{2} \mathrm{SiF}_{6}$, the ${ }^{29} \mathrm{Si}$ resonance is broadened beyond detection in the absence of ${ }^{19} \mathrm{~F}$ high-power decoupling. The ${ }^{19}$ F CRAMPS spectra were obtained using the MREV-8 pulse sequence (RHIM et al., 1973). The eight-pulse cycle time was 47.6 $\mu \mathrm{S}$, corresponding to a covered shift range of $158 \mathrm{ppm}$. Off-resonance effects were carefully checked. All chemical shift values are reported 
with the high-frequency positive convention. ${ }^{29} \mathrm{Si}$ shifts are reported with respect to external TMS $(0.0 \mathrm{ppm})$ and were measured by replacement with the secondary reference $\mathrm{Y}_{2} \mathrm{SiBe}_{2} \mathrm{O}_{7}(-73.3 \mathrm{ppm})$. ${ }^{27} \mathrm{Al}$ resonance positions (uncorrected for quadrupole induced shift) are reported with respect to aqueous $\mathrm{AlCl}_{3}$ solution $(0.0 \mathrm{ppm})$ and were measured by replacement of the sample with the standard. ${ }^{19} \mathrm{~F}$ CRAMPS shift values are reported with respect to $\mathrm{CFCl}_{3}(0.0 \mathrm{ppm})$ and were measured by mixing with a small amount of a secondary reference compound ( see Table 1). This was done in order to minimize the scaling factor errors, which arise from the MREV-8 pulse sequence. The shift values for the secondary reference compounds were established in single-pulse experiments by replacement of the sample with the standard. The ${ }^{19} \mathrm{~F} 90^{\circ}$ pulse lengths were set on the narrow ${ }^{19} \mathrm{~F}$ resonance of an organic polymer containing highly mobile $\mathrm{CF}_{3}$ groups ( $\mathrm{P}$. Jackson, pers. comm.). The same sample also served for shimming the probe and for setting up the CRAMPS experiment (JACKSON and HARRIS, 1988). In order to optimize resolution in the CRAMPS experiments, Delrin inserts were used in the $4 \mathrm{~mm}$ $\mathrm{ZrO}_{2}$ rotors. These inserts featured a small spherical sample cavity (ca. $2.8 \mathrm{~mm}$ in diameter) positioned at the center of the RF coil. A broad background ${ }^{19} \mathrm{~F}$ resonance from the Kel-F rotor caps was observed in fast-spinning ${ }^{19} \mathrm{~F}$ MAS spectra; however, no such background was observed under the conditions of ${ }^{19} \mathrm{~F}$ CRAMPS.

\section{RESULTS}

${ }^{19} \mathrm{~F}$ CRAMPS spectra are shown in Fig. 2. The spectra of the dry glasses $(a-c)$ contain some sharp spikes, which are experimental artifacts (rotor frequency lines, OLEJNICZAK et al., 1984). Aside from that, the spectra of dry and hydrous glasses are very similar. Both anhydrous and hydrous glasses show a strong resonance at $\approx-193 \mathrm{ppm}$. This is precisely the position of the ${ }^{19} \mathrm{~F}$ resonance in both crystalline $\mathrm{Na}_{3} \mathrm{AlF}_{6}$ and $\mathrm{K}_{3} \mathrm{AlF}_{6}$ (Table 1), which contain the $\mathrm{AlF}_{6}^{3-}$ complex anion (HAWTHORNE and FERGUSON, 1975). The fact that the ${ }^{19} \mathrm{~F}$ resonance of $\mathrm{Na}_{3} \mathrm{AlF}_{6}$ and $\mathrm{K}_{3} \mathrm{AlF}_{6}$ are identical, although those of $\mathrm{NaF}$ and $\mathrm{KF}$ are strongly different (Table 1 ), suggests that $F$ nuclei in the $A_{1 F}$ complex experience

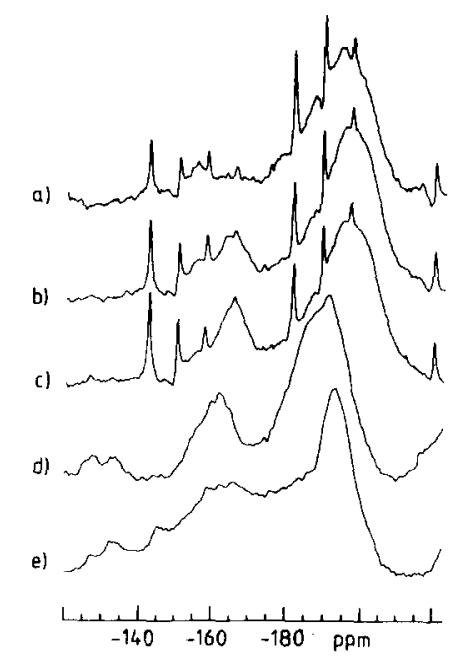

FIG. 2. ${ }^{19} \mathrm{~F}$ CRAMPS spectra obtained using the MREV-8 pulse sequence (RHIM et al., 1973). Chemical shifts in ppm relative to $\mathrm{CFCl}_{3}$. Experimental parameters: $90^{\circ}$ pulse width $=1.9 \mu \mathrm{s}$; eightpulse cycle time $=47.6 \mu \mathrm{s} ;$ MAS rate $=4-5 \mathrm{kHz}$; recycle delay $=15$ s. The number of accumulated FIDs is given in parentheses. All spectra were transformed with $150 \mathrm{~Hz}$ of line broadening. (a) Dry nepheline glass, 5.2 wt. $\% \mathrm{~F}$ (500). (b) Dry jadeite glass, 6.3 wt.\% F (500). (c) Dry albite glass, 5.8 wt.\% F (500). (d) Hydrous haplogranite glass, 2 wt.\% F (6862). (e) Hydrous haplogranite glass, 5 wt.\% F (2100).

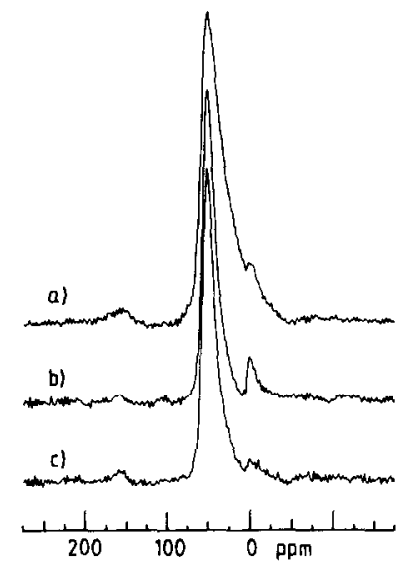

FIG $.3{ }^{27} \mathrm{Al}$ MAS spectra obtained under conditions of high power ${ }^{19} \mathrm{~F}$ decoupling (a) and (b) and without decoupling (c). Chemical shifts (uncorrected for quadrupolar effects) in ppm relative to dilute aqueous $\mathrm{Al}\left(\mathrm{H}_{2} \mathrm{O}\right)_{6}^{3+}$. Experimental parameters: MAS rate $=8 \mathrm{kHz}$; pulse length $=1 \mu \mathrm{s}(\pi / 12)$; recycle delay $=4 \mathrm{~s}$. The number of accumulated FIDs is given in parentheses. (a) Dry albite glass: 5.8 wt. $\% \mathrm{~F} ;{ }^{19} \mathrm{~F}$ decoupled; $\delta{ }^{27} \mathrm{Al}=+52.1$ and $-1.0 \mathrm{ppm}(80)$. (b) Hydrous haplogranite glass: $5 \mathrm{wt} . \% \mathrm{~F} ;{ }^{19} \mathrm{~F}$ decoupled; $\delta{ }^{27} \mathrm{Al}=+52.1$ and $+0.6 \mathrm{ppm}$ (616). (c) As for (b) but without decoupling.

little chemical interaction with the surrounding alkali cations. Therefore, we assign the resonance in the glasses to the octahedral $\mathrm{AlF}_{6}^{3-}$ complex. This interpretation is supported by the ${ }^{27} \mathrm{Al}$ MAS spectra (Fig. 3) of the dry and hydrous glasses. They show a weak resonance due to octahedral $\mathrm{Al}(\approx 0 \mathrm{ppm})$, in addition to the predominant signal of tetrahedral $\mathrm{Al}(\approx 52$ ppm; ENGELHARDT and MICHEL, 1987). While the resonance of tetrahedral $\mathrm{Al}$ is relatively sharp for the hydrous glasses (Fig. 3b), it is asymmetric with a shoulder on the low-frequency side for the anhydrous samples (Fig. 3a). KoHN et al. (1991) investigated the ${ }^{27} \mathrm{Al}$ spectra of similar F-containing glasses using a higher magnetic field strength. They showed that the shoulder on the low-frequency side of the ${ }^{27} \mathrm{Al}$ resonance of dry albite glass (Fig. 3a) is probably due to a small amount of five-coordinated Al. According to our data, this species appears not to be present in hydrous glasses (Fig. 3b). This observation is consistent with the work of $\mathrm{KOHN}$ et al. (1989), which suggested that introducing water into albite glass causes ordering of the structure and an increase of the symmetry of the $\mathrm{Al}$ environment.

The resonance of octahedral $\mathrm{Al}$ in the spectra of both hydrous and anhydrous glasses is considerably broadened if the high-power ${ }^{19} \mathrm{~F}$-decoupling is switched off (compare Fig. $3 \mathrm{~b}$ and $\mathrm{c}$ ). This confirms that at least part of the octahedral $\mathrm{Al}$ is coordinated by $F$. This observation also shows that a quantitative evaluation of the ${ }^{27} \mathrm{Al}$ spectra of $\mathrm{F}$-containing glasses is impossible without ${ }^{19} \mathrm{~F}$ decoupling because, in this case, a large part or even all of the Al coordinated by $\mathrm{F}$ will be hidden due to the broadening of the ${ }^{27} \mathrm{Al}$ resonance caused by dipolar interactions with ${ }^{19} \mathrm{~F}$. Estimates of the relative abundances of different $\mathrm{Al}$ species in the glasses given by KOHN et al. (1991) are therefore probably in error. Even with ${ }^{19} \mathrm{~F}$ decoupling, a quantitative interpretation of the ${ }^{27} \mathrm{Al}$ spectra is hardly warranted as the efficiency of the decoupling will not be equal over the entire ${ }^{19} \mathrm{~F}$ frequency range and probably never reaches $100 \%$. Several other potential problems with the 
quantification of ${ }^{27}$ Al spectra have been discussed by MERWIN et al. (1991) and in references given in that paper. If, for example, in the haplogranitc sample with $5 \mathrm{wt} \%$ fluorine, all or almost all of the $F$ were present as $\mathrm{AlF}_{6}$ complex, the intensity of the resonance of octahedral $\mathrm{Al}$ should be about $20 \%$ of that of tetrahedral Al. The observed intensity of the octahedral Al resonance (Fig. 3b) even with ${ }^{19} \mathrm{~F}$ decoupling is clearly less than that, which could be due to the presence of other F-containing species. However, incomplete efficiency of ${ }^{19} \mathrm{~F}$ decoupling and other effects (MERWIN et al., 1991) could just as well account for this observation. Therefore, no quantitative analysis of the ${ }^{27} \mathrm{Al}$ spectra is attempted in this paper.

The other ${ }^{19} \mathrm{~F}$ resonances observed (Fig. 2) cannot be unambiguously assigned based on the ${ }^{19} \mathrm{~F}$ spectra alone because they fall into a region where resonances both of $F$ bonded to Al and of F coordinated with Si can occur (Table 1). However, the presence of Si-F bonds appears to be rather unlikely on the basis of the ${ }^{19} \mathrm{~F} \rightarrow{ }^{29} \mathrm{Si} \mathrm{CP} / \mathrm{M} \wedge \mathrm{S}$ experiments. In these experiments, magnetization is transferred from the ${ }^{19} \mathrm{~F}$ to the ${ }^{29} \mathrm{Si}$ spin system. Spectra obtained by this method should, therefore, show a selective enhancement of the resonance of the portion of ${ }^{29} \mathrm{Si}$ that is coordinated by $\mathrm{F}$. However, the single-pulse ${ }^{29}$ Si MAS spectra and the ${ }^{19} \mathrm{~F} \rightarrow{ }^{29} \mathrm{Si} \mathrm{CP} / \mathrm{MAS}$ spectra are virtually identical for all contact times studied (2-100 ms; Fig. 4) and show only one resonance due to tetrahedral Si (KENNEDY and MCFARLANE, 1987; GRIMMER et al., 1980; THOMAS et al., 1983). In the ${ }^{19} \mathrm{~F} \rightarrow{ }^{29} \mathrm{Si} \mathrm{CP} /$ MAS experiments, the intensity of the resonance obtained depends on the contact time between the ${ }^{19} \mathrm{~F}$ and the ${ }^{29} \mathrm{Si}$ spin system. Figure 5 shows the intensities of the resonances as a function of contact time for two model compounds $\left(\mathrm{Na}_{2} \mathrm{SiF}_{6}\right.$ topaz, $\left.\mathrm{Al}_{2}(\mathrm{~F}, \mathrm{OH})_{2} \mathrm{SiO}_{4}\right)$ and for albite glass doped with $\mathrm{F}$. While $\mathrm{Na}_{2} \mathrm{SiF}_{6}$ contains direct Si-F bonds, $\mathrm{F}$ is coordinated with Al in topaz (RIBBE, 1982). For $\mathrm{Na}_{2} \mathrm{SiF}_{6}$, the maximum intensity of the ${ }^{29} \mathrm{Si}$ resonance is reached at a contact time of $10 \mathrm{~ms}$, but the maximum for topaz is at 20
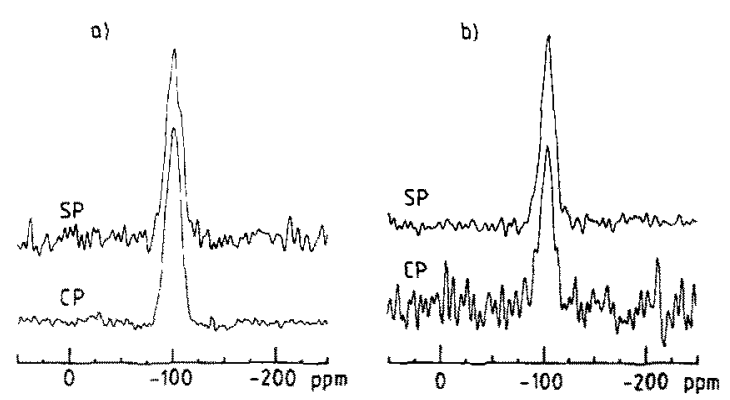

Fig. 4. ${ }^{29} \mathrm{Si}$ MAS spectra of (a) dry albite glass, $5.8 \mathrm{wt} . \% \mathrm{~F}$, and (b) hydrous haplogranite glass, $5 \mathrm{wt} \% \mathrm{~F}$. MAS rate $=4.1 \mathrm{kHz}$. All spectra were transformed without line broadening. (a) Top: singlepulse ${ }^{29} \mathrm{Si}$ MAS spectrum with high-power ${ }^{19} \mathrm{~F}$ decoupling; 380 transients; $30 \mathrm{~s}$ recycle delay; $3 \mu \mathrm{s} 40^{\circ}$ pulse; $\delta^{29} \mathrm{Si}=-100.5 \pm 0.2 \mathrm{ppm}$ Bottom: ${ }^{19} \mathrm{~F} \rightarrow{ }^{29} \mathrm{Si} \mathrm{CP} / \mathrm{MAS}$ spectrum. 568 transients; $20 \mathrm{~s}$ recycle delay; 20 ms contact time; $5 \mu \mathrm{s}{ }^{19} \mathrm{~F} 90^{\circ}$ pulse: $\delta^{29} \mathrm{Si}=-100.5 \pm 0.2$ ppm. (b) Top: single-pulse ${ }^{29} \mathrm{Si}$ MAS spectrum with high-power ${ }^{19} \mathrm{~F}$ decoupling. 360 transients; 30 s recycle delay; $3 \mu \mathrm{s} 40^{\circ}$ pulse; $\delta^{29} \mathrm{Si}$ $=-105.5+0.2 \mathrm{ppm}$. Bottom: ${ }^{19} \mathrm{~F} \rightarrow{ }^{29} \mathrm{Si} \mathrm{CP} / \mathrm{MAS}$ spectrum. 712 transients; $20 \mathrm{~s}$ recycle delay; $20 \mathrm{~ms}$ contact time; $5 \mu \mathrm{s}{ }^{19} \mathrm{~F} 90^{\circ}$ pulse: $\delta^{29} \mathrm{Si}=-105.5 \pm 0.2 \mathrm{ppm}$.
Relative intensities $|z|$

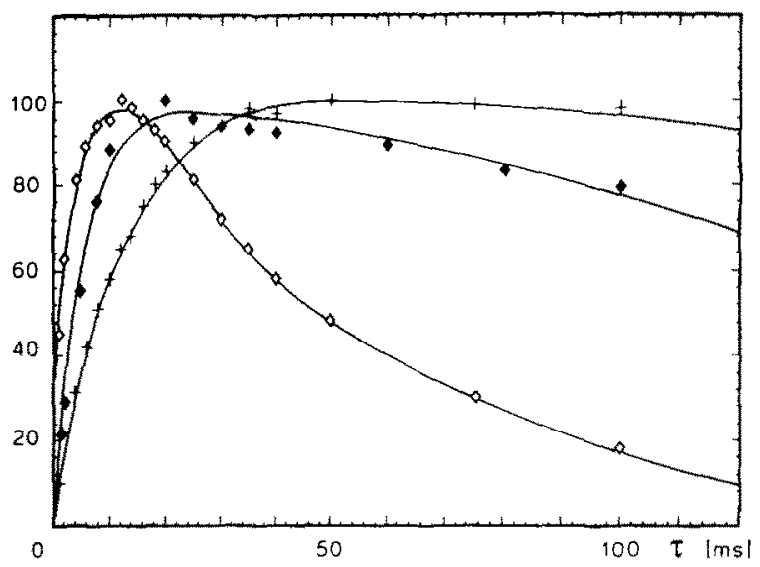

FIG. 5. Intensities of the ${ }^{19} \mathrm{~F} \rightarrow{ }^{29} \mathrm{Si} \mathrm{CP} / \mathrm{MAS}$ spectra of topaz $(\diamond), \mathrm{Na}_{2} \mathrm{SiF}_{6}(\diamond)$, and dry albite glass with $5.8 \mathrm{wt} \% \mathrm{~F}(+)$, plotted as a function of contact time. The vertical scale is in percent of the maximum of the respective curve. Each point on the curves is the result of the following: sixty-four transients with $20 \mathrm{~s}$ recycle delay and a MAS rate of $4.0 \mathrm{kHz}$, for topaz; sixty-four transients with 15 $s$ recycle delay and a MAS rate of $4.0 \mathrm{kHz}$, for $\mathrm{Na}_{2} \mathrm{SiF}_{5}$; and one hundred, eighty transients with $20 \mathrm{~s}$ recycle delay and a MAS rate of $4.1 \mathrm{kHz}$, for dry albite glass.

$30 \mathrm{~ms}$. In addition, at long contact times, the resonance intensity of the compound containing direct Si-F bonds $\left(\mathrm{Na}_{2} \mathrm{SiF}_{6}\right)$ decreases much more rapidly than in the case of topaz. The shape of the cross-polarization curve can therefore provide additional evidence on the presence or absence of $\mathrm{Si}-\mathrm{F}$ bonds in a sample. The maximum of the curve for $\mathrm{F}$ doped albite glass (Fig. 5) is at even longer contact times than for topaz, and after passing the maximum, the intensity decreases even more slowly. This is consistent with the absence of direct Si-F bonds in the glass samples. It was also found that the efficiency of the cross-polarization experiments strongly decreases with increasing water content of the glasses. This is additional evidence that, at least in the hydrous samples, $F$ is not coordinated with $\mathrm{Si}$, because the presence of water would not be expected io interfere with the transfer of magnetization from ${ }^{19} \mathrm{~F}$ to ${ }^{29} \mathrm{Si}$ if these nuclei were directly bonded. We therefore conclude that the resonance between -150 and -170 ppm in the ${ }^{19} \mathrm{~F}$ spectra (Fig. 2) is probably not caused by $\mathrm{Si}-\mathrm{F}$ units. Part of this resonance is actually a spinning sideband of the $\mathrm{AlF}_{6}$ resonance at $\approx-193 \mathrm{ppm}$. The remaining component could be due to $F$ anions bridging two octahedrally coordinated Al cations, as in crystalline $\mathrm{AlF}_{3}$ (EVANS, 1966), or by units containing octahedral Al coordinated by both $F$ and $O$, as in the crystal structure of topaz (RIBBE, 1982). The resonances of crystalline $\mathrm{AlF}_{3}$ and of topaz are at -174 and $-140 \mathrm{ppm}$, respectively (Table 1). Another possibility would be the presence of tetrahedral Al coordinated by $\mathrm{F}$ in the glasses.

Comparing the ${ }^{29} \mathrm{Si}$ spectra for F-containing glasses with those of glasses of equivalent composition without $F$ shows small, but significant, differences in the ${ }^{29} \mathrm{Si}$ shifts. While $\delta^{29} \mathrm{Si}$ is $-105.5 \mathrm{ppm}$ for the hydrous haplogranitic samples containing $5 \mathrm{wt}$ \% F, it is $-103.9 \mathrm{ppm}$ for a F-free glass of otherwise identical composition. Introducing $F$ into dry albite glass causes a similar shift of the ${ }^{29} \mathrm{Si}$ resonance toward lower 
frequency from $97.7 \mathrm{ppm}$ without $\mathrm{F}$ to $-101.6 \mathrm{ppm}$ with $5.8 \mathrm{wt} . \% \mathrm{~F}$ and ${ }^{19} \mathrm{~F}$ decoupling. Without decoupling, the ${ }^{29} \mathrm{Si}$ resonance of albite glass with $5.8 \mathrm{wt} . \% \mathrm{~F}$ is at $-100.8 \mathrm{ppm}$. Our ${ }^{29} \mathrm{Si}$ data for the F-free albite glass are in close agreement with those of OESTRIKE et al. (1987) and KOHN et al. (1989). The effect of $\mathrm{F}$ on the ${ }^{29} \mathrm{Si}$ spectra is probably due to the removal of some Al from the silicate network by complexing with $\mathrm{F}$. As Al has a deshielding effect on the Si resonance in an alumosilicate network (ENGELHARDT and MICHEL, 1987), this will result in a low-frequency shift for ${ }^{29} \mathrm{Si}$.

Changing the concentration of $F$ in the dry albite samples from 1.6 to $5.8 \mathrm{wt}$ \% or from 2 to $5 \mathrm{wt} . \%$ in the hydrous haplogranitic glasses has only a very minor effect on the ${ }^{19} \mathrm{~F}$ CRAMPS spectra (Fig. 2d, e). The presence of significant amounts of $\mathrm{F}$ coordinated to $\mathrm{K}$ or $\mathrm{Na}$ in the glasses appears unlikely on the basis of the ${ }^{19} \mathrm{~F}$ spectra because the resonances of crystallized $\mathrm{NaF}$ and KF fall far outside the range of the observed signals (Table 1). The absence of distinct $\mathrm{NaF}$ units in the glasses was confirmed by ${ }^{23} \mathrm{Na}$ MAS spectra. The ${ }^{23} \mathrm{Na}$ spectra of dry albite glass with 5 wt.\% $F$ and without $F$ arc exactly identical with a single resonance at $-23.2 \mathrm{ppm}$. The hydrous haplogranitic glasses show only a slight shift of the ${ }^{23} \mathrm{Na}$ resonance upon introduction of $\mathrm{F}$ into the matrix $(-17.0$ ppm without $\mathrm{F},-14.6 \mathrm{ppm}$ with $5 \mathrm{wt} . \% \mathrm{~F}) .{ }^{23} \mathrm{Na}$ spectra with and without ${ }^{19} \mathrm{~F}$ decoupling are exactly identical (Fig. 6). Sodium is probably present as a charge balancing cation which is not directly coordinated with $\mathrm{F}$.

In order to detect undissociated HF molecules in the hydrous samples, one hydrous haplogranite glass containing $\mathrm{D}_{2} \mathrm{O}$ instead of $\mathrm{H}_{2} \mathrm{O}$ was prepared. While ${ }^{19} \mathrm{~F}$ resonances due to fluorine coordinated with protons are typically very broad because of heteronuclear dipolar coupling, undissociated DF should give a much narrower resonance. However, only very subtle differences were observed between the spectra of the
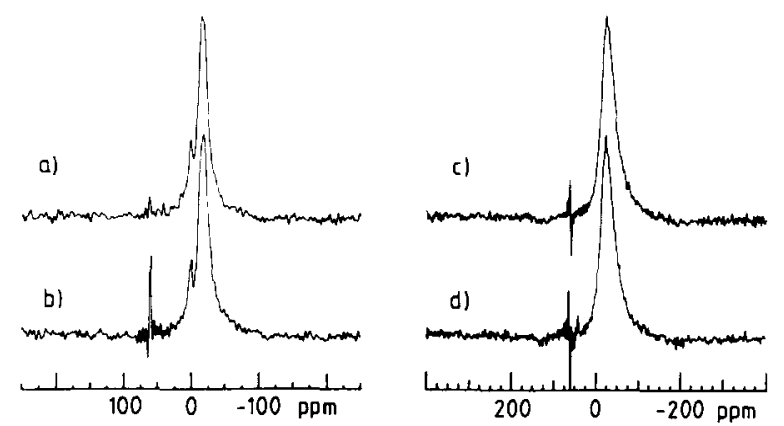

FIG. $6 .{ }^{23} \mathrm{Na}$ MAS spectra of hydrous haplogranitic glass ( $5 \mathrm{wt} . \%$ $\mathrm{F}$, left) and dry albite glass ( $5.8 \mathrm{wt} . \% \mathrm{~F}$, right) with and without highpower ${ }^{19} \mathrm{~F}$ decoupling. Peak positions are given with respect to $\delta^{23} \mathrm{Na}$ of solid $\mathrm{NaCl}=+7.1 \mathrm{ppm}$. Experimental parameters: $\mathrm{MAS}$ rate $=12$ $\mathrm{kHz}$; pulse length $=1 \mu \mathrm{s}(\pi / 12)$; recycle delay $=10 \mathrm{~s}$. The number of accumulated FIDs is given in parentheses. (a) Hydrous haplogranitic glass: 5 wt. $\%$ F; ${ }^{19}$ F decoupled; $-17.7 \mathrm{ppm} ;+0.4 \mathrm{ppm}$ (1000). (b) As for above but with no ${ }^{19} \mathrm{~F}$ decoupling (1000). (c) Dry albite glass: 5.8 wt. \% F; ${ }^{19} \mathrm{~F}$ decoupled; $-22.2 \mathrm{ppm}$ (400). (d) As for above but with no ${ }^{19} \mathrm{~F}$ decoupling ( 400$)$. The spike at $-60 \mathrm{ppm}$ in all spectra is an experimental artifact. It occurs because the $\mathrm{X}$-channel $/{ }^{19} \mathrm{~F}$ preamplifier matching box used is not optimized for the ${ }^{23} \mathrm{Na}$ resonance frequency. Rerunning the coupled ${ }^{23} \mathrm{Na}$ MAS spectra using a normal X-channel/1'H matching box, properly tuned for the ${ }^{23} \mathrm{Na}$ resonance frequency, yielded identical spectra without spike. deuterated and undeuterated haplogranitic samples, so that undissociated HF does not appear to be a major species in these glasses.

Our experimental results can be summarized as follows:

1) $\mathrm{F}$ coordinates preferentially with $\mathrm{Al}$ to form octahedral $\mathrm{AlF}_{6}^{3-}$ complexes in silicate glasses. An additional ${ }^{19} \mathrm{~F}$ resonance was detected, which could be caused by Al-F-Al bridges, by units containing octahedral $\mathrm{Al}$ coordinated by both $\mathrm{O}$ and $\mathrm{F}$, or by tetrahedral Al-F complexes.

2) The presence of Si-F bonds in the glasses studied appears to be very unlikely, although it cannot be ruled out entirely.

3) Over the range of compositions studied, the speciation of F seems to be similar in hydrous and anhydrous glasses and almost independent of the absolute $F$ concentration.

4) No clear evidence was found for coordination of F with alkalis. The environment of $\mathrm{Na}$ is very similar in F-containing and the corresponding F-free glasses. Undissociated HF does not appear to be a major species in the hydrous glasses.

5) As complexing by $\mathrm{F}$ removes $\mathrm{Al}$ from a network-forming position in the glasses, this should cause depolymerization of the silicate network.

\section{DISCUSSION}

Previous Raman-spectroscopic studies of highly polymerized aluminosilicate glasses (MYSEN and VIRGO, 1985a) showed evidence for depolymerization of the glass structure by $F$. This is consistent with our results which suggest removal of Al from the silicate network by complexing with F. However, this result does not necessarily apply to other glass compositions. Adding $\mathrm{F}$ to depolymerized melts might actually increase the degree of polymerization (FoLEY et al., 1986; LUTH 1988a,b). This effect is easy to understand. If $\mathrm{Al}$ is originally present as a network former, complexing of $\mathrm{Al}$ with $F$ will cause depolymerization. On the other hand, melts containing Al primarily as a network modifier will polymerize upon introduction of $\mathrm{F}$ into the system. In the absence of $\mathrm{Al}$, F might react with other network modifiers, which will also cause polymerization.

While Raman spectroscopy is useful to investigate the effect of $\mathrm{F}$ on the silicate network, little information can be obtained by this method on the speciation of F itself. In their study of $F$ in aluminosilicate glasses, MYSEN and VIRGO (1985a) suggested the presence of complexcs of $\mathrm{F}$ with $\mathrm{Na}$ and $\mathrm{Al}$ in their samples. However, with the possible exception of one weak band component observed in the most F-rich compositions studied, they could not find any direct evidence for these species because of their low scattering intensity.

One of the major conclusions of our work is the probable absence of Si-F bonds in the samples studied. MYSEN and VIRGO (1985a) reached the same conclusion. However, in their study of the joins $\mathrm{SiO}_{2}-\mathrm{AlF}_{3}$ and $\mathrm{SiO}_{2}-\mathrm{NaF}$ (MYSEN and VIRGO, 1985b), they observed a band between 930 and 940 $\mathrm{cm}^{-1}$, which they attributed to Si-F stretching vibrations. It is very much possible that these samples do indeed contain direct Si-F bonds as their composition is very different from those investigated in the present paper. However, the Ramanspectroscopic evidence presented by MYSEN and VIRGO 
(1985b) is not unambiguous. The band between 930 and $940 \mathrm{~cm}^{-1}$ could also be due to Si-O stretching vibrations of metasilicate groups, which typically occur in this region (MCMILlaN, 1984). In their study of F-containing aluminosilicate glasses, MYSEN and VIRGO (1985a) detected metasilicate and even pyrosilicate groups in the samples. It is not obvious why these structural units should not also be present in the glasses of the joins $\mathrm{SiO}_{2}-\mathrm{AlF}_{3}$ and $\mathrm{SiO}_{2}-\mathrm{NaF}$ (MYSEN and VIRGO, 1985b), which have a very similar overall degree of polymerization as the aluminosilicate glasses studied by MYSEN and VIRGO (1985a). In order to avoid volatilization of fluorides, MYSEN and VIRGo (1985b) synthesized their glasses in sealed Pt containers. $\mathrm{As} \mathrm{AlF}_{3}$ is known to be hygroscopic (GMELIN, 1934), a small amount of absorbed water in the starting mixture could also account for the band at $930-940 \mathrm{~cm}^{-1}$, as this is the typical region of SiOH stretching vibrations (STOLEN and WALRAFEN, 1976; MYSEN and VIRGO, 1986).

A quantification of the amounts of different species in Fcontaining glasses based on Raman spectroscopy is difficult because the dependence of the Raman-scattering cross sections on bulk composition is unknown for F-containing systems. Any speciation model derived from such spectra can therefore at best be semiquantitative. MYSEN and VIRGO (1985b) give data for the abundance of different species in glasses of the join $\mathrm{SiO}_{2}-\mathrm{AlF}_{3}$ and $\mathrm{SiO}_{2}-\mathrm{NaF}$. They suggest that there is little or no $\mathrm{F}$ coordinated with $\mathrm{Al}$, but a substantial amount of $\mathrm{NaF}$ was present in the glasses studied. They conclude that complexes of $\mathrm{F}$ with $\mathrm{Na}$ are more stable than those with $\mathrm{Al}$, which does not agree with our results. However, the entire calculation of MYSEN and VIRGO (1985b) is based on the assignment of the $930-940 \mathrm{~cm}^{-1}$ band to $\mathrm{Si}-\mathrm{F}$ vibrations. The possible problems with this assignment have already been pointed out. Furthermore, if one calculates the bulk F/Si molar ratio of the samples investigated by MYSEN and VIRGO (1985h) from the speciation model given in the same paper, the numbers obtained are much lower than according to the bulk composition of the samples. This suggests that some Frich species present in the samples were not detected.

\section{APPLICATIONS}

Our spectroscopic results suggest the removal of $\mathrm{Al}$ from bridging $\mathrm{AlO}_{4}$-tetrahedra by complexing with $\mathrm{F}$, which causes depolymerization of the melt. This mechanism explains the decrease of viscosity caused by F in silicate melts (DINGWELL et al., 1985; DINGWELL, 1989), and it might also be responsible for the effect of $F$ on diffusion coefficients. An extensive discussion of the physical properties of F-containing melts and their possible relationship to melt structure can be found in the paper by DINGWELL (1985).

Haplogranitic melts can be considered to be mixtures of $\mathrm{SiO}_{2}$, albite $\mathrm{NaAlSi}_{3} \mathrm{O}_{8}$, and the potash feldspar $\mathrm{KAlSi}_{3} \mathrm{O}_{8}$ component. The effect of replacing $\mathrm{O}$ with $\mathrm{F}$ (e.g., $3 \mathrm{O}=6$ $F$ ) in these melts can be rationalized by the following equation:

$$
3(\mathrm{Na}, \mathrm{K}) \mathrm{AlSi}_{3} \mathrm{O}_{8} \underset{-3 \mathrm{O}}{\rightarrow+6 \mathrm{~F}}(\mathrm{Na}, \mathrm{K})_{3} \mathrm{AlF}_{6}+\mathrm{Al}_{2} \mathrm{O}_{3}+9 \mathrm{SiO}_{2}
$$

Apparently, substitution of $O$ by $F$ reduces the activity of the feldspar component in the melt, while the activity of $\mathrm{SiO}_{2}$ increases. One would expect, therefore, that with increasing F content the eutectic composition in the haplogranite system contains more feldspar component and less $\mathrm{SiO}_{2}$. This is observed (MANNING, 1981); in fact, MANNING et al. (1980) proposed such a mechanism on the basis of their phase equilibria studies. Complexing of $\mathrm{Al}$ by $\mathrm{F}$ probably also accounts for the peraluminous composition of most F-rich granitic rocks.

The fact that both the position and the linewidth of the ${ }^{19} \mathrm{~F}$ resonance of $\mathrm{K}_{3} \mathrm{AlF}_{6}$ and $\mathrm{Na}_{3} \mathrm{AlF}_{6}$ matches almost precisely that of the glasses investigated suggests that there is little chemical interaction between the silicate component of the glass matrix and the $(\mathrm{Na}, \mathrm{K})_{3} \mathrm{AlF}_{6}$ complex in the glass. Therefore, one would expect a tendency of this system to unmix, which would explain the liquid immiscibility in Frich granitic melts found by GLYUK and ANFILOGOV (1973) and ANFILOGOV et al. (1973).

Experimental studies of the solubility of zircon, $\mathrm{ZrSiO}_{4}$ in F-containing, hydrous haplogranitic melts at $800^{\circ} \mathrm{C}$ and 2 kbar (KEPPLER, 1991) show a strong increase of the $\mathrm{Zr}$ content in the melt with increasing $\mathrm{F}$-concentration. $\mathrm{TiO}_{2}$ behaves similarly. EXAFS studies of the chemical environment of $\mathrm{Zr}$ in F-containing glasses (FARGES et al., 1991), however, show no evidence for any complexing of $\mathrm{Zr}$ by $\mathrm{F}$. Rather, $\mathrm{Zr}$ appears to be coordinated by $O$ in these glasses. The chemical equation for the decomposition of feldspar component in a haplogranitic melt by complexing of $\mathrm{Al}$ by $\mathrm{F}$ given above suggests that the introduction of $\mathrm{F}$ into the system results in an excess of $\mathrm{Al}_{2} \mathrm{O}_{3}$ component in the melt. This excess of $\mathrm{Al}_{2} \mathrm{O}_{3}$ will act as a network modifier and thereby make nonbridging oxygen ions available for complexing with high field strength ions, such as $\mathrm{Zr}$. This mechanism probably accounts for the enrichment of these ions in F-rich granitic melts.

Acknowledgments-L. Merwin and A. Sebald acknowledge financial support by the German Research Foundation (DFG). We appreciate reviews by I. Farnan, G. E. Brown, Jr., and two anonymous reviewers.

Editorial handling: G. Faurc

\section{REFERENCES}

ANFILogov V. N., Glyuk D. S., and Trufanova L. G. (1973) Phase relations in interaction between granite and sodium fluoride at water vapor pressure of $1000 \mathrm{~kg} / \mathrm{cm}^{2}$. Geochem. Intl $10,30-$ 33.

Burum D. P., EllemaN D. D., and RHIM W. K. ( 1978) A multiple pulse zero crossing NMR technique and its application to ${ }^{19} \mathrm{~F}$ chemical shift measurements in solids. I. Chem. Phys. 68, 11641169.

CONGDON R. D. and NASH W. P. (1988) High-fluorine rhyolithe: An eruptive pegmatite magma at the Honeycomb Hills, Utah. Geology 16, 1018-1021.

DINGWELL D. B. (1985) The structures and properties of fluorinerich magmas: A review of experimental studies. In Recent Advances in the Geology of Granite-Related Mineral Deposits (ed. R. P. TAYLOR and D. F. STRONG ) pp. 1-12. Canadian Institute of Mining and Metallurgy.

DINGWELL D. B. (1989) Effect of fluorine on the viscosity of diopside liquid. Amer. Mineral. 74, 333-338. 
Dingwell. D. B., Scarfe C. M., and Cronin D. J. (1985) The effect of fluorine on viscosities in the system $\mathrm{Na}_{2} \mathrm{O}-\mathrm{Al}_{2} \mathrm{O}_{3}-\mathrm{SiO}_{2}$ : Implications for phonolites, trachytes and rhyolites. Amer. Mineral. 70, 80-87.

ENGELHARDT G. and MiCHEL D. (1987) High Resolution Solid State NMR of Silicates and Zeolithes. John Wiley \& Sons.

Evans R. C. (1966) An Introduction to Crystal Chemistry, 2nd ed. Cambridge University Press.

Farges F., Ponader C. W., and Brown G. E., JR. (1991) Structural environments of incompatible elements in silicate glass/melt systems: 1. Zirconium at trace levels. Geochim. Cosmochim. Acta 55, 1563-1574.

FleEI M. E. (1986) X-ray diffraction and spectroscopic studies on the structure of silicate glasses and melts. Mineralogical Association of Canada Short Course Handbook 12, 1-35.

FolEY S. F., TAYLOR W. R., and GREEN D. H. (1986) The effect of fluorine on phase relationships in the system $\mathrm{KAlSiO}_{4}-\mathrm{Mg}_{2} \mathrm{SiO}_{4}$ $\mathrm{SiO}_{2}$ at $28 \mathrm{kbar}$ and the solution mechanism of fluorine in silicate melts. Contrib. Mineral. Petrol. 93, 46-55.

Glyuk D. S. and ANFILOGov V. N. (1973) Phase equilibria in the system granite- $\mathrm{H}_{2} \mathrm{O}-\mathrm{HF}$ at a pressure of $1000 \mathrm{Kg} / \mathrm{cm}^{2}$. Geochem. Intl. 10, 321-325.

GMELIN L. (1934) Handbuch der Anorganischen Chemie, Aluminium Teil $B$. 8th ed. Verlag-Chemie.

GrimMer A. R., WeIKEV W., VON LAMPE F., FEChNER E., Peter R., and Molgedey G. (1980) Hochauflösendes ${ }^{29} \mathrm{Si}$ NMR an festen Silikaten: Anisotropie der chemischen Verschiebung im Thaumasit. Z. Chem. 20, 453.

HaWTHORNE F. C. and FERGuSON R. B. (1975) Refinement of the crystal structure of cryolite. Canadian Mineral. 13, 377-382.

HAYASHI S., KIRKPATRICK R. J., and DINGWELL D. B. (1987) MASS NMR study of F-containing $\mathrm{Na}_{2} \mathrm{O}-\mathrm{Al}_{2} \mathrm{O}_{3}-\mathrm{SiO}_{2}$ glass (abstr.), Eos 68, 436.

JACKSON P. and HARRIS R. K. ( 1988) A practical guide to combined rotation and multiple-pulse NMR spectroscopy. Magn. Reson. Chem. 26, 1003-1011.

KENNEDY J. D. and MCFARLANE W. (1987) Silicon, germanium, tin and lead. In Multinuclear NMR (ed. J. MASON) pp. 305-333. Plenum Press.

KEPPLER H. (1991) Influence of fluorine on the solubility of high field strength trace elements in granitic melts (abstr.). Eos 72, 1991 Fall Mtg. Suppl., 532-533.

KEPPLER H. and WYLLIE P. J. (1990) Role of fluids in transport and fractionation of uranium and thorium in magmatic processes. Nature 348, 531-533.

Klein Douwel C. H., Maas W. E. J. R., Veeman W. S., Werumeus BUNING G. H., and VANKAN J. M. J. (1990) Miscibility in PMMA/ Poly (vinylidene fluoride) blends studied by fluorine-19-enhanced carbon-1 3 CPMAS NMR. Macromolecules 23, 406-412.

KoHn S. C., Dupree R., and SMITH M. E. (1989) A multinuclear magnetic resonance study of the structure of hydrous albite glasses. Geochim. Cosmochim. Acta 53, 2925-2935.

Kohn S. C., Dupree R., Mortuza M. G., and Henderson C. M. B. (1991) NMR evidence for five- and six-coordinated aluminium fluoride complexes in F-bearing aluminosilicate glasses. Amer. Mineral. 76, 309-312.

Koster VAN Groos A. F. and Wyllie P. J. (1968) Melting relationships in the system $\mathrm{NaAlSi}{ }_{3} \mathrm{O}_{8}-\mathrm{NaF}-\mathrm{H}_{2} \mathrm{O}$ to 4 kbars pressure. I. Geol. 76, 50-70.

KoVALENKO V.I. (1973) Distribution of fluorine in a topaz-bearing quartz keratophyre dike (ongonite) and solubility of fluorine in granitic melts. Geochem. Intl. 10, 41-49.

Kreinbrink A. T., Sazavsky C. D., Pyrz J. D., Nelson D. G. A., and HONKONEN R. S. ( 1990) Fast-magic-angle-spinning ${ }^{19}$ F NMR of inorganic fluorides and fluoridated apatitic surfaces. J. Magn. Reson. 88, 267-276.

LUTH R. W. (1988a) Raman spectroscopic study of the solubility mechanisms of $\mathrm{F}$ in glasses in the system $\mathrm{CaO}-\mathrm{CaF}_{2}-\mathrm{SiO}_{2}$. Amer. Mineral. 73, 297-305.

LUTH R. W. (1988b) Effects of $F$ on phase equilibria and liquid structure in the systems $\mathrm{NaAlSiO}_{4}-\mathrm{CaMgSi}_{2} \mathrm{O}_{6}-\mathrm{SiO}_{2}$. Amer. Mineral. 73, 306-312.

MANNING D. A. C. (1981) The effect of fluorine on liquidus phase relationships in the system Qz-Ab-Or with excess water at $1 \mathrm{~kb}$. Contrib. Mineral. Petrol. 76, 206-215.

ManNing D. A. C., Hamilton D. L., Henderson C. M. B., and DEMPSEY M. J. (1980) The probable occurence of interstitial Al in hydrous, F-bearing and F-free aluminosilicate melts. Contrib. Mineral. Petrol. 75, 257-262.

MCMILLAN P. ( 1984) Structural studies of silicate glasses and melts-applications of Raman spectroscopy. Amer. Mineral. 69, 622-644.

MEHRING M. (1970) Spin-decoupling in the resolution of chemical shifts in solids by pulsed NMR. $J$. Chem. Phys. 54, 3239-3240.

MERWIN L. H., SEBALD A., RAGer H., and SCHNEIDER H. (1991) ${ }^{29} \mathrm{Si}$ and ${ }^{27} \mathrm{Al}$ MAS NMR spectroscopy of mullite. Phys. Chem. Minerals 18, 47-52.

MYSEN B. O. and VIRGO D. (1985a) Structure and properties of fluorine-bearing aluminosilicate melts: The system $\mathrm{Na}_{2} \mathrm{O}-\mathrm{Al}_{2} \mathrm{O}_{3}$ $\mathrm{SiO}_{2}-\mathrm{F}$ at 1 atm. Contrib. Mineral. Petrol. 9, 205-220.

MYSEN B. O. and VIRGO D. (1985b) Interactions between fluorine and silica in quenched melts on the joins $\mathrm{SiO}_{2}-\mathrm{AlF}_{3}$ and $\mathrm{SiO}_{2}-\mathrm{NaF}$ determined by Raman spectroscopy. Phys. Chem. Minerals 12, $77-85$.

MYSEN B. O. and VIRGO D. (1986) Volatiles in silicate melts at high pressure and temperature. 1. Interaction between $\mathrm{OH}$ groups and $\mathrm{Si}^{4+}, \mathrm{Al}^{3+}, \mathrm{Ca}^{2+}, \mathrm{Na}^{+}$and $\mathrm{H}^{+}$. Chem. Geol. 57, 303-331.

Oestrike R., Yang W. H., KirkPatrick R. J., Hervig R. L., NAVROTSKY A., and MONTEZ B. (1987) High-resolution ${ }^{23} \mathrm{Na}$, ${ }^{27} \mathrm{Al}$ and ${ }^{29} \mathrm{Si}$ NMR spectroscopy of framework aluminosilicate glasses. Geochim. Cosmochim. Acta 51, 2199-2209.

OleJNiCZAK E. T., Roberts J. E., Vega S., and GRIFFin R. G. (1984) Rotor frequency lines in multiple-pulse/magic-angle sample spinning NMR spectra. J. Magn. Reson. 56, 156-162.

Pines A., GibBy M. G., and Waugh J. S. (1973) Proton-enhanced NMR of dilute spins in solids. $J$. Chem. Phys. 59, 569-590.

PONADER C. W. and BROWN G. E., JR. (1989) Rare-earth elements in silicate glass / melt systems: II. Interactions of $\mathrm{La}, \mathrm{Gd}$, and $\mathrm{Yb}$ with halogens. Geochim. Cosmochim. Acta 53, 2905-2914.

RhIM W. K., Elleman D. E., and VaughN R. W. (1973) Analysis of multiple pulse NMR in solids. J. Chem. Phys. 59, 3740-3749.

RibBe P. H. (1982) Topaz. Rev. Mineral. 5, 215-230.

Sebald A., Merwin L., SCHaller T., and KNÖller W. (1992) Cross polarization from ${ }^{19} \mathrm{~F}$ to ${ }^{29} \mathrm{Si}$ and ${ }^{19} \mathrm{Sn}$. J. Magn. Reson. (in press).

STEMPROK M. (1982) Tin-fluorine relationships in ore-bearing assemblages. In Metallization Associated with Acid Magmatism (ed. A. M. Evans) pp. 321-337. John Wiley \& Sons.

STOLEN R. H. and WALRAFEN G. E. (1976) Water and its relation to broken bond defects in fused silica. $J$. Chem. Phys. 64, 26232631.

Taylor R. E., Pembleton R. G., Ryan L. M., and Gerstein B. C. (1979) Combined multiple pulse NMR and sample spinning: Recovery of proton chemical shift tensors. J. Chem. Phys. 71, 4541-4545.

Thomas J. M., Gonzales-Calbert J. M., Fyfe C. A., Gobbi G. C., and NICHOL M. (1983) Identifying the coordination of silicon by magic-angle-spinning NMR: Stishovite and quartz. Geophys. Res. Lett. 10, 91-92. 